\title{
Aldo Ferrer
}

\section{Ira deuda externa y las políticas nacionales}

\section{EL MARGO INTERNAGIONAL}

Se conocen, desde hace tiempo, las causas principales que dieron lugar a la rápida expansión del financiamiento privado internacional en el último cuarto de siglo. Pero las tensiones recientes con. tribuyen a destacar ciertos rasgos importantes de la cuestión. Desde fines de la década de 1950, los recursos y la cartera de los bancos que operan a escala mundial aumentó a una tasa promedio del $30 \%$ anual. El mercado de eurodólares se convirtió en el núcleo del sistema financiero internacional. La fuente principal de recursos del sistema fue el déficit del balance de pagos de los Estados Unidos. Por ser el dólar un activo de reserva para el resto del mundo, los Estados Unidos tuvieron el privilegio de financiar su desequilibrio "exportando" su moneda nacional. La liquidez que se fue acumulando en los bancos centrales se filtró progresivamente hacia la banca privada aumentando su capacidad prestable. Otros dos factores influyeron en la expansión de la liquidez disponible en la banca internacional. En primer lugar, el desarrollo de las actividades de las corporaciones transnacionales y la expansión de sus excedentes financieros. En segundo término, a partir de 1973, la formación de un cuantioso superávit en los países exportadores de petróleo.

El aumento de la liquidez internacional, la liberación de los flujos de fondos entre las economías industriales, la expansión de las corporaciones y de la banca transnacional, provocaron una estrecha integración entre las plazas financieras de los principales países. Los movimientos de capitales de corto plazo alcanzaron una gran importancia. Las paridades cambiarias quedaron sometidas a las corrientes especulativas generadas en las expectativas de los operảdores económicos y en los cambios en las políticas de los principales paises. Las corrientes de crédito internacional se insertaron, así, en un marco de creciente peso de las actividades financieras y de integración transnacional de las plazas locales.

Es importante observar que la expansión del financiamiento in- 
ternacional en el curso de la década de 1970 se produjo, simultáneamente, con un cambio drástico en las tendencias imperantes en la producción y comercio mundiales. Como consecuencia del acrecentamiento de las presiones inflacionarias en los países centrales, las políticas económicas comenzaron a adquirir un marcado sesgo restrictivo. La tentativa de disciplinar el comportamiento de los agentes económicos mediante la contención de la demanda $y^{r}$ la restricción monetaria frenó el aumento de la producción y el comercio internacionales. En tales condiciones, se produjo una sensible disminución de la demanda de crédito dentro de los mismos países desarrollados. La banca internacional se vio estimulada, así, a buscar nuevos destinos para su creciente capacidad prestable.

En este contexto, los países en desarrollo fueron ganando un atractivo creciente para la banca internacional. En el curso de la década de 1970, esos países enfrentaron un desequilibrio creciente en sus pagos internacionales. En esto influyeron dos factores. Primero, el debilitamiento de sus exportaciones por el rezago del comercio internacional que deprimió, también, los términos de intercambio de las exportaciones de alimentos y materias primas, Segundo, el aumento de los precios del petróleo y su impacto en los países importadores del hidrocarburo. La convergencia entre Ia capacidad prestable excedente en la banca internacional y la mayor clemanda de financiamiento externo en los países en desarrollo provocó un rápido incremento del endeudamiento de estos últimos. De este modo, la cartera de la banca internacional con ese destino pasó a representar una proporción sustancial de sus operaciones totales. Actualmente, sobre una cartera activa total del orden de un billón de dólares, cerca de $1 / 3$ está colocada en el Tercer Mundo y, dentro de éste, en aquellos países de mayor dimensión y potencial. América Latina ocupa una posición dominante ${ }^{1}$. Cerca del $50 \%$ de los préstamos de la banca internacional al mundo en desarrollo corresponde a México, Brasil y Argentina.

Estas tendencias provocaron una modificación sustancial en las prácticas de ajuste de los pagos internacionales. Hasta la década de 1960, el Fondo Monetario Internacional había ejercido una función de vigilancia de los desequilibrios de los países en desarrollo y de sus políticas de ajuste. Cada vez que debía enfrentarse un déficit en los pagos externos, la opinión del Fondo era importante para acceder a los préstamos de la banca privada y pública internacional. Esto se diluyó en la década de 1970. Interesados en expandir sus préstamos al Tercer Mundo, los bancos privados ignoraron cualquier tipo de condicionalidad y presionaron fuertemente para aumentar sus préstamos y, naturalmente, sus ganancias.

\footnotetext{
${ }^{1}$ Las economlas centralmente planificadas de Europa Oriental ganaron también participación en las operaciones de la banca transnacional. Actualmente, el 69 de su cartera activa corresponde a préstamos a las economfas del Este.
} 
Este proceso entró en crisis a principios de la década de 1980. Tres factores contribuyeron a desencadenar las tensiones en que se debate hoy el sistema financiero internacional. En primer lugar, el continuado deterioro de la capacidad de pagos externos de los países deudores por el debilitamiento del comercio internacional y la caída de sus términos de intercambio. En segundo término, el brusco aumento de la tasa de interés internacional debido a las políticas monetarias restrictivas seguidas en los Estados Unidos desde finales de la Administración Carter. Finalmente, la dimensión alcanzada por el endeudamiento de los países comprometidos. En tales condiciones, los servicios de la deuda exceden ampliamente la capacidad de pagos de los deudores y convierten en inviables las tradicionales políticas de ajuste. Estas fueron concebidas para enfrentar desequilibrios menores de los pagos externos. Nunca para resolver situaciones en las cuales los intereses de la deuda rondan o exceden el $50 \%$ de los ingresos de exportación.

La crisis del endeudamiento de los países en desarrollo se ubica en un contexto de dificultades generalizadas. La desaceleración del crecimiento de la producción y el comercio mundiales y la persistencia de las presiones inflacionarias, provocan la situación más difícil de la economía internacional desde la década de 1930. El desempleo en los Estados Unidos y el resto del mundo industrializado alcanza los niveles más altos registrados desde aquel entonces. El debilitamiento de las ventas de las empresas de los países industriales, sumado al aumento de las tasas de interés, genera una situación de insolvencia en segmentos importantes de las economías industriales.

Las quiebras de empresas han aumentado fuertemente en los países industriales. En 1982 han alcanzado un record histórico en los Estados Unidos y en Gran Bretaña aumentaron 35\% sobre las del año anterior. En Canadá, los créditos bancarios impagos en 1982 son tres veces mayores que en 1981. No se trata sólo de la caída de empresas medianas y pequeñas. Importantes corporaciones transnacionales están engrosando la lista de quiebras. Por ejemplo, dos gigantes de la industria del tractor, Massey Fergurson e International Harvester, tienen deudas de difícil cumplimiento que ascienden, en conjunto, a más de $\$ 5.000$ millones. La quicbra de AEG en Alemania, se ubica en el mismo contexto. Los problemas del sector productivo se trasladan a las entidades financieras. En Italia, la caída del Banco Ambrosiano y la decisión de las autoridades italianas de no respaldar a la filial del Banco en Luxemburgo y en los Estados Unidos, la caída del Penn Square Bank y de la Drysdale Government Securities, son algunas de las manifestaciones del impacto de la situación económica real en el sector financiero. Como existen fuertes conexiones entre las entidades, los problemas de unas se transfieren a otras. Por ejemplo, la Drysdale Government Securities dejó de pagar us\$160 millones al Chase Man- 
hattan, que ha declarado una pérdida de us\$285 millones por sus operaciones con la Drysdale. Entidades financieras tradicionales de los Estados Unidos han sido excluidas de la nómina de bancos de primera línea, y esto aumenta su costo en la captación de fondos del mercado. La crisis de confianza está desplazando fondos desde Ios certificados de depósitos de los bancos privados en las Letras de Tesorería de los Estados Unidos.

El comportamiento de los grandes agregados macroeconómicos confirman estos hechos. Entre 1973 y 1981 , el producto bruto a precios corrientes de los países industriales aumentó en $150 \%$ y su deuda bancaria con las entidades de esos mismos países creció en $250 \%$. Como la tasa de interés pasó, entre los mismos años, del $8 \%$ al $17 \%$, la relación entre los intereses pagados y el producto aumentó del $5 \%$ en 1973 al $15 \%$ en 1981. Si se comparan los intereses pagados por el crédito interno e internacional de los bancos de los principales mercados financieros con el valor del comercio mundial, se observan tendencias semejantes. En 1973, los intereses pagados equivalían al $25 \%$ de las exportaciones mundiales y en 1981 al $70 \%$. Estas relaciones entre costos financieros y magnitudes vinculadas a la producción y el comercio ilustran acerca del origen de la actual crisis financiera internacionàl.

La banca privada del mundo desarrollado enfrenta, pues, turbulencias generalizadas que comprometen la solvencia y viabilidad de numerosas entidades. No deben extrañar, pues, el desasosiego $y$ la crisis de confianza en que se debate, actualmente, el sistema financiero internacional. En este contexto, el nivel de compromiso de los bancos con los deudores del Tercer Mundo adquiere perfiles particularmente críticos. La deuda de Argentina, Brasil y México con los nueve principales bancos de los Estados Unidos, excede el capital propio de esos mismos bancos. En el marco de dificultades generalizadas, la falencia de uno o más de los principales países deudores comprometería la estabilidad de buena parte del sistema. De allí la preocupación de los bancos centrales de las eco" nomías industriales y de sus gobiernos por diseñar mecanismos que permitan enfrentar la crisis existente y la eventual cesación de pagos de uno o más de los deudores principales. Las soluciones no son fáciles, porque el problema abarca al sistema económico internacional tal y como viene funcionando desde el fin de la Segunda Guerra Mundial.

La experiencia contemporánea revela que el sistema internacional no puede seguir operando con políticas restrictivas en los países centrales, altas tasas de interés y un endeudamiento creciente. La hipertrofia del sector financiero y el debilitamiento de las fuentes de crecimiento de la producción, termina por generar desequilibrios insoportables y una crisis que no tiene solución con las políticas económicas tradicionales, ni en los países industriales ni en el mundo en desarrollo. La crisis de los paradigmas teóricos y de 
las polfticas predominantes en los Estados Unidos y el resto de los países avanzados, revela la profundidad del problema y el replanteo inevitable de las relaciones rigentes en el orden económico mundial.

\section{LAS POLÍ́tIGAS NACIONALES}

Las tendencias dominantes en el sistema financiero internacional revelan que el endeudamiento de los países en desarrollo fue promovido por la banca transnacional. Se admite actualmente en los medios competentes, que los bancos fueron extremadamente imprudentes en la búsqueda del negocio y en su política de penetración en las plazas periféricas. Pero esto apenas explica el contexto internacional del fenómeno del endeudamiento. No ilustra acerca de cómo y para qué se endeudaron los países afectados. Para tener un panorama del fenómeno es indispensable observar las políticas seguidas dentro de cada país y su inserción en las tendencias internacionales apuntadas. De manera general puede afirmarse que la abundancia de crédito internacional aflojó las políticas de ajuste de los pagos internacionales de los países en desarrollo. Es natural. Era más fácil obtener créditos que realizar políticas más rigurosas de sustitución de importaciones, promoción de exportaciones y ahorro de energía. No es que esto no se hubiera hecho. Por ejemplo, Brasil realizó avances considerables en la sustitución y ahorro de energía y en la expansión de sus exportaciones. De todos modos, cabe admitir que la abundancia de crédito internacional financió desequilibrios externos insostenibles en ausencia de aquella circunstancia.

La relación entre la deuda externa y las variables económicas significativas (producción, acumulación de capital, salarios, etc.), fue decisivamente condicionada por las políticas económicas aplicadas en cada país. Desde esta perspectiva, en América Latina, cabe distinguir dos experiencias principales. La de aquellos países que se endeudaron manteniendo el paradigma tradicional de sus politicas de industrialización y desarrollo. Y la de aquellos otros que, simultáneamente, cambiaron radicalmente sus políticas previas y promovieron la apertura externa en torno de las ventajas comparativas reveladas por el mercado internacional. EI primer grupo abarca a Brasil y México, el segundo a los países del Cono Sur y, especialmente, por su dimensión e importancia, a la Argentina.

En el primer grupo se observa el mantenimiento de un rápido crecimiento económico, una sostenida expansión de la acumulación de capital y el aumento del empleo. Entre 1975 y 1981, la economía brasileña creció casi un $40 \%$ y la mexicana casi un $60 \%$. Esto mantuvo una fuerte demanda de importaciones vinculada a la formación de capital y a crecientes niveles de actividad económica in- 
terna. Brasil enfrentó este proceso expansivo, mientras el aumento de los precios del petróleo acrecentaba el déficit de sus pagos externos. El ahorro de energía y la expansión de las exportaciones no pudo evitar el fuerte crecimiento del endeudamiento. En México, el petróleo jugó un papel distinto. Desde fines de la Administración Echeverría, el hidrocarburo emergió como una importante fuente de divisas. Este cuadro de abundancia de la capacidad de pagos externos estimuló un sostenido proceso de acumulación pero, también, una imprudente política cambiaria. Durante toda la Administración López Portillo, la moneda mexicana mantuvo la paridad en torno de 25 pesos por dólar. Como la inflación interna excedió la internacional, el peso se revaluó sostenidamente. Esto estimuló las importaciones y desalentó las exportaciones distintas del petróleo, incluyendo el turismo, que es muy importante como generador de empleo y fuente de divisas. La revaluación del peso, sumada al aumento de las tasas de interés y al deterioro del mercado petrolero, desató la crisis. El cambio de expectativas de los operadores económicos y el convencimiento bien fundado de que la paridad cambiaria era insostenible, promovió la fuga de capitales. El Presidente López Portillo proporcionó, en su último mensaje al Congreso, datos espectaculares: los inmuebles y activos financieros en el exterior, propiedad de mexicanos, es del orden de los 50.000 millones de dólares. Es decir, que, en gran parte, el incremento de la deuda externa tiene como contrapartida, la fuga de capital nacional. Sea como fuere, tanto en México como en Brasil, el endeudamiento acompañó un sostenido crecimiento de la producción, el empleo y la formación de capital. Ambos países ratificaron sus políticas de industrialización, integración de sus espacios territoriales y formación de sistemas productivos crecientemente complejos.

En la Argentina (y también en Chile y Uruguay), la experiencia es muy distinta. En este país, el creciente acceso al crédito internacional se produjo simultáneamente con un cambio espectacular de la política económica. Toda la experiencia industrialista y sustitutiva de importaciones fue responsabilizada de la irracionalidad económica y el atraso del país. La alternativa consistiría en volver a abrir la economía argentina, asignar los recursos conforme a las ventajas comparativas reveladas por el mercado internacional, deprimir los salarios reales para aumentar la rentabilidad privada y desmantelar al sector público para reubicar al mercado como mecanismo esencial de la distribución del ingreso y la asignación de recursos. Naturalmente, estas políticas provocaron la violenta caída de la producción, el empleo y los salarios reales. En tales condiciones, era imposible generar una demanda acrecentada de crédito externo. Antes bien, dada la contracción de la demanda intexna, caeteris paribus, el balance comercial y la cuenta corriente del balance de pagos tendrían que haber mostrado un superávit considerable y el Banco Central un aumento de sus reservas internacio- 
nales. Para aumentar la corriente de crédito externo era indispensable, por lo tanto, forzar el endeudamiento. Así se hizo por varias vías: el desplazamiento del financiamiento público al crédito externo, la reducción de aranceles de importación y, sobre todo, la revaluación del peso. En definitiva, terminó castigéndose a las exportaciones y subsidiando la fuga de capitales, las importaciones y otros gastos en el exterior como turismo, utilidades y regalías. El incremento de los gastos en equipos militares importados contribuyó en el mismo sentido.

A diferencia de Brasil y México, el endeudamiento argentino se produjo en el marco de la contracción económica y la destrucción de riqueza. Entre 1975 y 1981, la deuda con los bancos privados internacionales (que representa en los tres páses más de $2 / 3$ de la deuda total), aumentó de esta manexa: México 4 veces, Brasil, 3,5 veces y Argentina 7 veces. Pero la producción aumentó así: México $57 \%$, Brasil $37 \%$ y Argentina cero. El financiamiento externo en Brasil y México integró un proceso de rápida expansión de la acumulación financiada con ahorro interno. En Argentina ocurrió Io contrario. La brecha entre el ahorro interno del período 1976-81 y el ahorro potencial que se hubiera alcanzado, con apenas mantener la tasa de crecimiento histórico, implicó una contracción de la acumulación de capital del orden de los 20.000 millones de dólares. Por otra parte, suponiendo, conservadoramente, que la relación producto/capital en la industria es de 1 a 3 , que el producto industrial es del orden de los 25.000 millones de dólares y que el parque industrial desmantelado en el último sexenio representa el $30 \%$ del activo fijo reproducible existente en el sector manufacturero, la destrucción de capital industrial se acerca a los 30.000 millones de dólares. Si a esto se suma la reducción del stock de ganado vacuno en 10 millones de cabezas, se concluye que, en el sexenio 1976-81, el incremento de la deuda externa es más de 30.000 millones de dólares fue acompañado por una destrucción de capital propio que excede los 50.000 millones de dólares.

La experiencia de Argentina y también, la de Chile y Uruguay que guarda, con aquella, muchos rasgos comunes, no tiene equivalente en el plano internacional. La deuda de otros países importantes, como Corea, también fue acompañada, como en Brasil y México, por un sostenido crecimiento de la producción, la acumulación y el empleo. En el caso de las economías de Europa Oriental, las diferencias institucionales impiden extraer conclusiones comparativas válidas. En el Cono Sur de la América Latina, la expansión del crédito internacional en el marco de políticas internas de cuño monetarista provocó el peor de los mundos posibles: deudas inmensas y un fenomenal deterioro de la economía y el bienestar. Naturalmente, estas diferencias del proceso de endeudamiento asumen hoy mucha importancia, cuando todos los países deudores y la 
misma comunidad financiera internacional, enfrentan el desafío de resolver con realismo los desequilibrios existentes.

\section{EL PROCESO DE AJUSTE}

Sean cuales fueran las causas y las condiciones del endeudamiento de los países en desarrollo, el problema asume dimensiones globales y compromete, simultáneamente, a acreedores y deudores. Más aún, agrava la inestabilidad prevaleciente en el sistema internacional. La interrupción brusca de las corrientes de financiamiento privado al mundo en desarrollo, agrava los problemas mismos deI ajuste $\mathrm{y}$ arriesga con desencadenar la falencia de los deudores. Pero, además, đeprimirá aún más el comercio internacional que, en la última décacla, se sostuvo, en parte, por las importaciones del mundo en desarrollo financiadas, precisamente, con el crédito internacional. Por otro lado, todos los países deudores enfrentan situaciones sociales y políticas complejas. En América Latina, prevalecen condiciones de pobreza y tensión social que comprometen la estabilidad de los países afectados y repercuten en el orden mundial.

Frente a este cuadro de situación, los criterios tradicionales de la banca internacional y del Fondo Monetario Internacional han perdido gran parte de su vigencia. La llamada "receta Polak", inspirada por el ex asesor económico del FMr, se funda en la modificación de los precios relativos en favor de los bienes exportables y en la contención del gasto público y la oferta monetaria, para deprimir la demanda interna. En tales condiciones, se supone que aumentan las exportaciones, disminuyen las importaciones y se restablece el equilibrio. Como el Fondo y la comunidad financiera internacional tienen una fuerte inclinación por el libre comercio (en los países periféricos), la receta incluye la unificación de los tipos de cambio y la liberación comercial.

Esta estrategia de ajuste se aplicó numerosas veces en la América Latina en los últimos treinta años. Los resultados fueron generalmente negativos en relación a la producción y el empleo, pero al menos, lograron, casi siempre, restablecer el equilibrio de los pagos internacionales. Las diferencias de criterios acerca de la naturaleza de la inflación y el desequilibrio externo nutrieron, desde la década de 1950, el debate entre la escuela estructuralista latinoamericana y el enfoque ortodoxo promovido por el FMr. El reverdecimiento del paradigma monetarista durante la década de 1970, transitó por otros carriles. Influyó, por una parte, la abundancia de financiamiento privado internacional ya apuntada y, por la otra, el llamado "enfoque monetario del balance de pagos". Este subordinó la política monetaria y el proceso de ajuste a la libertad de las transacciones de fondos externos y de la tasa de interés. En tales condiciones, el ajuste reproducía la práctica vigente en los tiempos del patrón oro, cuando las variaciones de reservas de oro modi- 
ficaban la liquidez y la tasa de interés y el ajuste se producía automáticamente. El apego a este enfoque en el Cono Sur, terminó con el desastre que se observa hoy en las economías del área.

El sistema financiero internacional, hondamente preocupado por sus problemas y las dificultades que enfrentan sus deudores, se inclina actualmente por volver a fortalecer el papel del FMrr. El Fondo fue marginado en la época que, The Economist, acaba de definir como "la fiesta". Ahora, sus normas de condicionalidad vuelven a ser vistas como un requisito indispensable para sanear las economías endeudadas y restablecer la confianza en sus acreedores. Pero las condiciones han cambiado. Probablemente, parte de la respuesta que la comunidad internacional debe adoptar frente a estos problemas transitará por FMI. Pero la receta tradicional ha dejado de ser viable. En esto influyen tres factores principales. Primero, la dificultad de que la devaluación de las monedas nacionales realmente aumente las exportaciones cuando están cayendo los términos de intercambio, aumenta el proteccionismo y se debilita la expansión del comercio mundial. Segundo, la prevalencia de tasas de interés reales que siguen siendo exageradamente altas para los países deudores. Tercero, la dimensión misma del endeudamiento.

En tales condiciones, los servicios de la deuda exceden cualquier posibilidad de ajuste por las vías tradicionales. Guando sólo los intereses alcanzan o superan el $50 \%$ del valor de las exportaciones, es prácticamente imposible generar un excedente en el balance comercial y los pagos corrientes que permita cumplir los servicios. Conviene insistir. La receta tradicional de ajuste fue concebida para otras circunstancias, no para las actuales. Esto se está comprendiendo en la comunidad financiera internacional y repercutirá probablemente en los criterios del FMI. Un análisis realista de la situación indica que todos los participantes del proceso deberán modificar criterios tradicionales. Hay que encontrar fórmulas que permitan enfrentar los desequilibrios en el marco de la recuperación económica de los países deudores y de los mismos países industriales. Las posiciones rígidas son hoy la vía más segura a la cesación de pagos de los deudores y al colapso de buena parte del sistema financiero internacional. Es probable que la actual fase de ansiedad y desconcierto que predomina en las plazas financieras internacionales sea sustituida, a corto plazo, por respuestas a los dilemas actuales, pragmáticos y viables. Pero no hay que hacerse ilusiones. El problema de la deuda forma parte de los conflictos de fondo existentes en el orden mundial, del apetito de las potencias hegemónicas por conservar sus viejas posiciones de dominio y de la lucha del mundo en desarrollo por superar el atraso y la dependencia. Lo nuevo en este cuadro de situación es que, muchos países en desarrollo, han alcanzado ya el potencial suficiente como para defender con firmeza sus intereses y que la proliferación del poder en el orden mundial amplía las opciones abiertas a cada uno de ellos. 
Las relaciones de poder son menos asimétricas que antes. Las opciones nacionales se definen, fundamentalmente, dentro de cada pais.

En la respuesta a la crisis, los deudores tienen la responsabilidad principal. Sea cual fuere la reacción de la comunidad financiera internacional, los deudores enfrentan, inexorablemente, la necesidad del ajuste de sus pagos externos. El problema no consiste en si hay que ajustar o no. El problema real radica en cómo ajustar. Es improbable, por lo menos a corto plazo, que continúe el incremento del endeudamiento de los países en desarrollo. Los bancos serán reticentes frente a nuevas demandas de crédito, pero deberán ser todo lo flexible que haga falta para renovar la deuda existente y gran parte de los intereses. Es decir, que cada país deberá poner su casa en orden. Las reglas del juego han cambiado. La capacidad de respuesta de cada país dependerá, en gran medida, de su potencial interno, de la diversificación de sus recursos, de su capacidad de exportar y sustituir importaciones. Pero el ajuste habrá que hacerlo. Cada país deberá acostumbrarse a vivir dentro de sus propios medios. Por lo menos, hasta tanto se restablezca la confianza en el sistema financiero internacional y los banqueros vuelvan a desarrollar su negocio que no es, naturalmente, reducir los préstamos y sus carteras activas, sino aumentar las corrientes de crédito. Cuando ese momento llegue, seguramente la experiencia de los últimos años provocará modificaciones importantes en el comportamiento de deudores y acreedores. Mientras tanto, los deudores deben enfrentar con firmeza el proceso de ajuste de sus cuentas internacionales. En lo fundamental, las deudas no serán reducidas. Serán refinanciadas. Pero, el incremento del endeudamiento será probablemente pequeño a corto y mediano plazo.

Los dilemas que enfrentan nuestros países son realmente complejos: cómo equilibrar los pagos internacionales sin frenar el crecimiento ni agravar la pobreza que afecta a amplios sectores sociales. El rebote político interno de las tensiones internacionales es importante. La decisión del gobierno de México de nacionalizar la banca privada nacional revela que, confrontados con riesgos sociales $y$ políticos internos, los gobiernos se inclinarán por modificar las reglas del juego. Seguramente, la comunidad financiera internacional está tomando nota de estas advertencias. Al mismo tiempo, debe observarse que el problema de la deuda está concentrado en los países mayores y más avanzados dentro del mundo en desarrollo. La crisis se plantea cuando varios de estos países han alcanzado ya un potencial de acumulación, diversidad de recursos y capacidad de administración de la economía, considerables. Las respuestas internas no son sólo indispensables. Parecen, también, posibles.

En definitiva, la posibilidad de cada país de administrar su deuda y asegurar su ajuste externo, transita por la solidez de su sistema político y la representatividad de sus cuadros dirigentes. La 
deuda está ligada a poderosos intereses y a visiones que pueden comprometer la adopción de políticas realistas de balance de pagos y desarrollo económico. Sea como fuere, la administración de la deuda y la vinculación entre las plazas financieras interna e internacional dificulta la conducción de la polf́tica fiscal y monetaria. Por ejemplo, Brasil no ha podido impedir, en los últimos dos años, altas tasas de interés y un proceso recesivo que interrumpe el sostenido crecimiento a largo plazo de su economía. En verdad, el endeudamiento y su administración forma parte del diseño global de la política económica, de los objetivos de los grupos dirigentes, de la firmeza de los objetivos nacionales de cada país. Esto es particularmente cierto en la Argentina, en donde la cuestión de la deuda aparece enmascarada en problemas más profundos, que hacen a los objetivos globales de la política económica y a la administración misma del sistema de poder.

\section{EL CASO ARGENTINO}

La deuda externa de los países latinoamericanos y del resto del mundo en desarrollo tiene una dimensión internacional y otra interna. La primera es suficientemente diáfana y abarca tendencias bien conocidas en el funcionamiento del sistema económico munclial. La segunda, se plantea en el ámbito nacional de cada país. El endeudamiento externo se vincula a las tendencias del desarrollo económico, la asignación de recursos y la distribución del ingreso. En definitiva, el sector financiero interno y sus vinculos con las plazas transnacionales configura una compleja madeja de intereses que afecta a todo el aparato productivo y al sistema de poder. La formación de los paradigmas teóricos y las propuestas de política económica no son ajenos a estas relaciones profundas entre el plano financiero, la deuda externa y el sistema económico real. Así sucede, también, en la Argentina.

Según los datos compilados por el Banco de Ajustes Internacionales de Basilea, excluyendo a las economías industriales, a fines de 1981, Argentina era el tercer deudor de la banca privada internacional después de México y Brasil. Su deuda representaba el $8 \%$ de la de todos los países en desarrollo no exportadores de petróleo y alrededor del $70 \%$ del endeudamiento total del país que, a fines de 1982, asciende a los 40.000 millones de dólares. Más del $50 \%$ de la deuda con la banca privada internacional tiene vencimiento hasta un año de plazo. Este es el peor perfil temporal dentro del mundo en desarrollo, con la excepción de Corea. Los intereses del endeudamiento total representan, en 1982, alrededor del $60 \%$ del valor de las exportaciones. La deuda argentina con la banca internacional aumentó 7,2 veces entre 1975 y 1981, lo cual representa el ritmo más rápido de endeudamiento a escala mundial.

En este trabajo se procuró encuadrar el endeudamiento latino- 
americano dentro de las tendencias imperantes en el orden mundial y de las políticas predominantes en los países deudores. En relación al caso argentino, las conclusiones son las siguientes:

1. La deuda de los países en desarrollo con la banca internacional fue promovida por una agresiva política de préstamos de las entidades acreedoras. Como epílogo de este proceso, los países deudores se encuentran con un volumen de compromisos que excede su capacidad de pagos y los bancos acreedores tienen una cartera fuertemente comprometida en préstamos al mundo en desarrollo. La deuda argentina se multiplicó en el marco de un cambio drástico de la política económica, una fenomenal destrucción de riqueza y el agudo deterioro de las condiciones sociales.

2. La crisis de confianza desatada en el sistema financiero internacional obedece a los niveles de deuda, al aumento de las tasas de interés y al deterioro de la capacidad de pagos externos de los deudores. La crisis de confianza abarca al mismo mundo desarrollado como consecuencia de los bajos niveles de actividad imperantes, la calda de rentabilidad de la actividad privada y las altas tasas de interés real que imperan en las plazas financieras.

3. La dimensión de la crisis es tal que las recetas tradicionales de ajuste promovidas por el FMr han dejado de ser viables. Se observa una apreciación creciente de este hecho. Esto genera las ambivalencias $\mathrm{e}$ incertidumbres que predominan actualmente en los círculos financieros internacionales. No hay política ortodoxa alguna que logre, vía la contracción de la demanda interna y el estímulo exportador, generar los excedentes necesarios para pagar siquiera los intereses de la deuda. El refinanciamiento de las amortizaciones y de la mayor parte de los intereses, es la única alternativa de los bancos para no forzar la cesación de pagos de sus principales deudores. Se observa, también, un convencimiento creciente de que la solución de la crisis depende de una modificación de las tendencias imperantes en la economía mundial. Vale decir, el reinicio del crecimiento de la producción y el comercio mundiales y la reducción de las tasas de interés. La futura capacidad de pagos de los deudores depende, en gran medida, de esta modificación de las tendencias internacionales.

4. La capacidad de presión de los acreedores está seriamente limitada por la inviabilidad de las recetas tradicionales de ajuste y por los riesgos políticos inherentes a cualquier tentativa cle deprimir severamente el nivel de actividad, empleo y salarios en los países deudores. La iniciativa en el manejo de la deuda se ha desplazado hacia estos últimos pero ellos deben, de todas maneras, restablecer el equilibrio de sus pagos corrientes excluyendo los intereses de la deuda ${ }^{1}$. No es previsible, en las condiciones actuales, un in-

${ }^{1}$ Es interesante observar la reacción de la comunidad financiera internacional frente a las actuales dificultades de los pagos externos de México. En definiti- 
cremento de la deuda por encima de la refinanciación de las amortizaciones y todo o parte de los intereses. El problema de los deudores no transita por si deben o no ajustar sus pagos externos sino por cómo hacerlo.

5. Desde la perspectiva de los deudores, la dimensión interna del problema asume una importancia decisiva. La forma en que se encare el proceso de ajuste depende, esencialmente, de las opciones políticas de cada sociedad, de la estructura de poder y de la consistencia de las políticas económicas globales. Los vínculos entre los círculos financieros internacionales, las plazas locales y el sistema interno de poder, condicionan la orientación de las políticas que se adoptan para alcanzar el ajuste externo y ubicar el cumplimiento de la deuda en el contexto más amplio de la estrategia económica global.

En el marco de estas conclusiones, deben destacarse los siguientes rasgos de la situación argentina:

1. El balance comercial registra un considerable superávit y lo mismo ocurre con la cuenta corriente, excluyendo los intereses de la deuda. En ciertas condiciones, Argentina puede mantener el equilibrio de sus pagos básicos (sin intereses de la deuda) al mismo tiempo que repuntan la producción, el empleo y los salarios reales. La Argentina está cercana al autoabastecimiento energético $y$ es excedentaria en alimentos. Una firme política exportadora y de sustitución de importaciones, permitiría el repunte de la producción, manteniendo el equilibrio de los pagos básicos. Asentada sobre estas bases, la posición negociadora argentina dista de ser insostenible. En un reciente editorial, (septiembre 10), el Financial Times caracterizaba la situación argentina en los siguientes términos: "si se elimina el servicio de la deuda, Argentina queda con un superávit en su balance de comercio y puede desarrollar su comercio sobre bases de contado. En tales circunstancias, las presiones financieras y políticas desde el exterior, digamos desde los Estados Unidos, pueden lograr poco. Los banqueros sólo pueden esperar y conservar sus esperanzas". Vivir al contado. Esta es, en efecto, una posibilidad real de la Argentina, que debe tomarse en cuenta en el diseño de la estrategia de ajuste externo y de la posición negociadora con los acreedores.

2. La Argentina tiene excelentes antecedentes como país cumplidor de sus compromisos internacionales. Transitó toda la crisis de la década de 1930 sin dejar de cumplir. La última vez en que el país entró en cesación de pagos fue en 1890. Hace casi un si-

va, la esperanza de los banqueros parece descansar en la posibilidad de que eI futuro Presidente de México sea más "razonable" que el actual. 
glo. Por otra parte, su potencial básico lo sigue convirtiendo en un buen sujeto de crédito internacional. Como señala el mismo editorial del Financial Times: "El problema con la Argentina es que la crisis política puede impedir decisiones racionales". Esto es, en efecto, lo que está ocurriendo. Debido al vacío de poder y al manejo errático del régimen cambiario y de los controles existentes, la sobrefacturación de importaciones y subfacturación de exportaciones, retenciones de stocks y otras maniobras, están diluyendo el superávit comercial que debería estar registrándose. Se ha acumulado, así, un considerable atraso en las deudas comerciales que está trabando las corrientes normales de importaciones y el abastecimiento de insumos esenciales. La deuda financiera y el comercio son dos campos diferenciados con vínculos entre ellos pero que, en las condiciones actuales, no deben confundirse. Si los atrasos de la deuda comercial y la fuga de divisas generan una situación de desabastecimiento de insumos importados, el país entrará en la negociación externa maniatado por las dificultades crecientes de su actividad productiva. En verdad, el problema actual no son los banqueros ni el Fondo Monetario Internacional. Radica en la propia irracionalidad del comportamiento interno y en los mismos sectores responsables del desastre actual y de la deuda externa.

Estas reflexiones sobre el contexto internacional y el caso argentino, permiten extraer conclusiones adicionales. El desequilibrio actual de los pagos externos del país es distinto al que imperaba en las fases críticas del modelo de "contención y arranque". Esta situación se parece más a la imperante en las economías europeas después de la guerra. Esta es la tesis central de mi último libro². El país debe enfrentar su deuda externa, simultáneamente con la reconstrucción del aparato productivo y la eliminación de los desequilibrios fundamentales del sistema, cuya manifestación más evidente es la hiperinflación. Ninguna economía europea se hubiera reconstruido después de 1945 con estrategias ortodoxas de ajuste. Lo hicieron controlando estrictamente las variables fundamentales del sistema, con programas rigurosos de economía de divisas y movilizando la actividad productiva. Esta es la única respuesta válida para la situación argentina. Las restricciones para una política realista de ajuste externo y de cumplimiento de la deuda, en el marco de la reconstrucción, no están colocadas fuera de las fronteras del país, sino dentro.

De allí que la deuda externa no sea el problema más importante ni las políticas para encararla la primera prioridad a que debería responder la conducción económica. La deuda es una tercera prioridad. La primera es la reconstrucción institucional y el establecimiento de un poder político estable capaz de administrar con firmeza las variables fundamentales del sistema económico. La única

'Ia postguerra. El Cid, Buenos Aires, 1982. 
forma de lograrlo es el retorno a un régimen representativo, en el marco de la Constitución Nacional. Sólo un régimen legítimo puede cumplir dos requisitos previos para encarar con éxito el problema de la deuda. Prinero, la capacidad de convocatoria interna y la movilización del país detrás de objetivos compartidos. Segundo, la recuperación del prestigio internacional seriamente erosionado, en los últimos años, por la violación de los valores fundamentales de nuestra cultura y de los principios polf́ticos que predominan en el mundo occidental. Por lo tanto, si se pregunta qué es lo primero que hay que hacer para pagar la deuda externa, la respuesta es: transferir el poder y cerrar definitivamente la instancia de los gobiernos de facto. En este contexto, la segunda prioridad es la puesta en marcha de una política de reconstrucción y desarrollo que fortalezca los pagos internacionales. Cumplidas estas dos condiciones, el problema de la deuda tiene respuestas posibles. Ningún sector importante del país está planteando, como alternativa válida, desconocer la deuda y dejar de pagarla. El problema radica, en cómo hacerlo. La solución descansa, en definitiva, en el ámbito interno y en las opciones políticas que se asuman. 